The European Journal of Public Health, Vol. 27, No. 4, 775-780

(c) The Author 2017. Published by Oxford University Press on behalf of the European Public Health Association. All rights reserved.

doi:10.1093/eurpub/ckx041 Advance Access published on 11 April 2017

\title{
Inequalities in obesity in Portugal: regional and gender differences
}

\author{
Luís Alves ${ }^{1,2,3}$, Silvia Stringhini ${ }^{4}$, Henrique Barros ${ }^{1,2}$, Ana Azevedo ${ }^{1,2}$, Pedro Marques-Vidal ${ }^{5}$ \\ 1 EPIUnit - Institute of Public Health of the University of Porto (ISPUP), Porto, Portugal \\ 2 Department of Clinical Epidemiology, Predictive Medicine and Public Health, University of Porto Medical School, Porto, \\ Portugal \\ 3 ICVS/3B's - PT Government Associate Laboratory, Life and Health Sciences Research Institute (ICVS), School of Medicine, \\ University of Minho, Braga, Portugal \\ 4 Institute of Social and Preventive Medicine (IUMSP), University Hospital Centre, Biopole 2, Lausanne, Switzerland \\ 5 Department of Medicine, Internal Medicine, Lausanne University Hospital (CHUV), Lausanne, Switzerland
}

Correspondence: Pedro Marques-Vidal, Office BH10-642, CHUV, 46, rue du Bugnon 1011 Lausanne, Switzerland, Tel: +41 2131409 34, e-mail: pedro-manuel.marques-vidal@chuv.ch

Background: Obesity levels vary considerably according to geographical region and socio-economic status. We evaluated the prevalence of obesity by education and occupational position across seven Portuguese regions. Relative and absolute inequalities in obesity were also assessed. Methods: Data was drawn from the Portuguese Health Survey 2005/6 (26 674 adults, 46.6\% women). Education was categorized as $\leq 4,5-11$ and $\geq 12$ complete years of education. Occupational position was grouped as upper white collar, lower white collar and blue collar. The Relative Index of Inequality (RII) and the Slope Index of Inequality (SII) were used to quantify relative and absolute inequalities in obesity, respectively. Results: In women, prevalence of obesity ranged between $10.0 \%$ (Algarve) and 20.3\% (Azores); in men, it ranged between $13.3 \%$ (Algarve) and $16.4 \%$ (Lisbon). In women, the educational RII (95\% confidence interval) ranged between 2.4 (1.1 to 5.1) in the Centre and 6.6 (3.0 to 14.2 ) in Alentejo, and the SII (95\% Cl) between 9.7 ( -1.3 to 20.7$)$ and 33.0 (26.0 to 40.0$)$, respectively. In men, the RII ranged between 0.8 (0.4 to 1.5) in Madeira and 1.9 (1.0 to 4.5) in the Centre, and the SIl between $-8.3(-19.0$ to 2.5 ) and 9.5 ( -0.1 to 19.1$)$, respectively. Occupational Rlls were similar to those for education, although somewhat lower. Conclusion: In Portugal, large educational and occupational inequalities in obesity are observed, but they vary considerably by region and are larger among women than men.

\section{Introduction}

O besity is an important public health issue ${ }^{1}$ with serious health, social and economic consequences. This led the World Health Organization to develop a global strategy on diet, physical activity and health. ${ }^{2}$ In 2005, the prevalence of obesity in the adult Portuguese population was $16.0 \%$ among women and $14.3 \%$ among men. ${ }^{3-5}$ However, the increase in the age-standardized prevalence of obesity differed across geographical regions of the country. Between 1999 and 2005, the largest absolute increases occurred in the North $(+4.7 \%)$ and Lisbon regions $(+4.6 \%)$, whereas smaller variations were found in the Centre $(+2.2 \%)$ and Alentejo regions $(+2.6 \%)^{6}{ }^{6}$

Obesity is also unevenly distributed across societal groups. In high-income countries, obesity is more prevalent among people of lower socioeconomic position (SEP). ${ }^{7}$ Although many studies assessed inequalities in obesity using regional or national population samples, ${ }^{8-11}$ fewer addressed regional variations in inequalities within the same country. ${ }^{12}$ If regional heterogeneity in inequalities is found, the study of its determinants could provide additional information on the mechanisms underlying these inequalities. Further, gathering information on inequalities at the local level may support and facilitate the planning and implementation of local policies to decrease health disparities.

Thus, this study aimed to estimate and compare the socioeconomic differences in the prevalence of obesity across the seven level II Nomenclature of Territorial Units for Statistics (NUTS) regions in Portugal. We used data from the 2005/6 National Health Survey and we selected education and occupational position as indicators of SEP. ${ }^{13}$ Additionally, we examined regional variations in relative and absolute inequalities in obesity using the Relative and Slope Indexes of Inequality.

\section{Methods}

\section{Study sample}

Data from the $4^{\text {th }}$ Portuguese Health Survey was provided by Statistics Portugal upon request. The $4^{\text {th }}$ National Health Survey was a cross-sectional, multistage cluster sampling, nationwide population-based survey conducted between February 2005 and January 2006; its methodology has been described previously. ${ }^{6}$ Briefly, the target population was the people living in family households, subjects living in collective housings (i.e. monasteries) being excluded. Trained interviewers collected data according to a standardized protocol in computer-assisted face-to-face interviews. Participation rate (percentage of households who responded) was $76 \%$. The final number of interviews was 41193.

For the current analyses, participants aged $\geq 20$ years that reported a principal occupation not related to the army, and whose employment status over the previous two weeks was active worker, unemployed or retired were considered eligible $(n=27212)$. We excluded subjects with missing information on education, occupation and self-reported height/weight $(n=538$, corresponding to $2.0 \%$ of the eligible sample), leaving a final sample size of 26674 (46.6\% women). For 18819 cases $(70.5 \%)$ the information was provided directly by the interviewee, and for $7,855(29.5 \%)$ by a proxy (Supplementary figure S1). 


\section{Variables definition}

Seven regions, five in mainland Portugal (North, Centre, Lisbon, Alentejo and Algarve) and the two autonomous regions (Azores and Madeira) were considered (Supplementary figure S2). ${ }^{14} \mathrm{~A}$ description of the characteristics of the regions for years 2005 and 2006 is provided in supplementary table S1. Gross domestic product was obtained from Eurostat ${ }^{15}$; urbanization rates from the Portuguese household budget survey; ${ }^{16}$ unemployment rates for 2001 (not available for years 2005 and 2006) for each gender were obtained from PORDATA. ${ }^{17}$

Age was categorized as $20-39,40-59$ and 60 years or more. Education was assessed as the number of school years completed and categorized as less than 5 years, 5-11 years and 12 years or more. Occupation was assessed with the question 'What is (was) your main job?' and categorized in three groups: upper white collar (executive civil servants, industrial directors, scientists, middle management and technicians), lower white collar (administrative and related workers, service and sales workers) and blue collar (farmers, skilled and unskilled workers, craftsmen, machine operator and assembly workers). ${ }^{13}$ Participants with no precise occupation such as students and women staying at home were excluded from the analyses. Height and weight were self-reported. Body mass index (BMI) was calculated as the ratio weight $(\mathrm{kg}) /$ height $(\mathrm{m})$ squared. Obesity was defined by a $\mathrm{BMI} \geq 30 \mathrm{~kg} / \mathrm{m}^{2} .{ }^{18}$

The relative index of inequality (RII) and the slope index of inequality (SII) were calculated for education and occupation. Both indexes are summary measures recommended when comparing populations. ${ }^{19}$ Instead of comparing the two most extreme SEP groups, these measures take into account both the size and relative position of each group in the respective SEP hierarchy. In the present study, education was transformed into a summary measure ranging from zero (highest level of education) to one (lowest level of education). The population in each educational category was assigned a score corresponding to the midpoint of the relative position of their category in the cumulative population distribution. ${ }^{20}$ For example, if the category with the highest level of education included $10 \%$ of the population, the range of the individuals in this category would be from 0 to 0.10 , giving a mid-point of 0.05 , which would be the value assigned to this category; if the next higher level of education category included $20 \%$ of the population, its range would be from $0.1-0.3$, thus it would be assigned a value of 0.20 and so on. ${ }^{21}$ The RII can be interpreted as the prevalence ratio and the SII can be interpreted as the prevalence difference between the extremes of the educational hierarchy.

\section{Statistical analysis}

Statistical analyses were performed using STATA version 14.1 for Windows ${ }^{\circledR}$ (Stata Corp, College Station, TX, USA). All analyses were stratified by gender. Frequency weights were used to obtain estimates representative of the Portuguese population of $2005 .{ }^{6}$ The age, education and occupation distributions of respondents were compared across economic regions using Pearson chi-square tests.

For the whole country and for each region, the gender-specific weighted prevalence of obesity in each category of education and occupation was standardized using age categories 20-39, 40-59 and $60+$ of the European standard population. Weighted logistic regression models were used to grade differences in the prevalence of obesity across educational and occupational groups within each region, using obesity as outcome and SEP as a continuous variable, adjusting for the same age categories.

The age-adjusted association between obesity prevalence and the RII or SII was assessed using log-binomial regression models, as logistic regression models may produce biased estimates when the prevalence of the outcome is relatively high. ${ }^{22}$ Specifically, we used generalized linear models with a logarithmic link function to estimate RIIs and with an identity link function to estimate SIIs, each with the respective 95\% confidence intervals (95\% CI), as previously proposed. ${ }^{23}$ In order to assess whether the magnitude of relative or absolute inequalities varied after taking into account other confounders such as urbanization and unemployment rate, we computed the RII and SII for Portugal adjusting for age and for the following regional characteristics: gross domestic product (model 2); percentage of the population living in an urban setting (model 3); unemployment rate (model 4) and the three variables together (model 5).

As proxies might provide biased information regarding individual characteristics such as height and weight and thus obesity status, analysis was performed on direct interview, and a further sensitivity analysis was conducted using all eligible interviews with data (Supplementary figure S1).

\section{Results}

\section{Education and occupation}

The distribution of participants by age, educational and occupational groups according to gender and region is provided in supplementary table S2 and the corresponding weighted percentages are provided in table 1. Approximately half of Portuguese women and men were in the lowest educational groups. Five out of ten Portuguese women and six out of ten Portuguese men declared a blue collar occupation. Large regional differences in the proportion of women and men with a low educational or occupational level were found. Low educational level (weighted percentages) ranged from 32.0\% (Azores) to $58.5 \%$ (Alentejo) in women and between $38.6 \%$ (Lisbon) and $58.0 \%$ (Alentejo) in men, table 1. Similarly, blue collar occupation ranged from $32.7 \%$ (Azores) to $59.3 \%$ (North) in women, and between $50.5 \%$ (Lisbon) and $67.7 \%$ (Alentejo) in men, table 1.

Overall prevalence of obesity was slightly higher in women than in men. When age-standardized, weighted data were used, lower educational and occupational levels had higher prevalence rates of obesity in women, while no such consistent association was found in men (table 2). Using non-standardized, non-weighted data, lower educational and occupational levels had higher prevalence rates of obesity in both genders, the difference being stronger in women than in men (supplementary table S3).

\section{Obesity prevalence, overall and by educational or occupational group}

The gender-specific, age-standardized, weighted prevalence of obesity according to educational or occupational group are summarized in table 2. Among women, there were large differences in the prevalence of obesity across regions, ranging from $11.6 \%$ (Algarve) to $20.6 \%$ (Alentejo). The prevalence of obesity increased with decreasing level of education and occupation in almost every region, Madeira excepted (table 2). In men, smaller differences in the prevalence of obesity were observed between regions, ranging from $14.7 \%$ (Algarve) to $18.1 \%$ (Alentejo). Contrary to women, no clear graded pattern was observed in men, although obesity was generally more common in lower educational and occupational groups.

\section{Relative and absolute educational inequalities in obesity}

The educational and occupational RII and SII regarding obesity for Portugal and the seven regions are summarized in table 3. Overall, Portuguese women with the lowest education were over three times more likely to be obese than their most educated counterparts. Large regional variations in RIIs were also found, ranging from 3.1 (Algarve) to 5.9 (Alentejo). Absolute differences in the prevalence of obesity also varied considerably between regions, ranging from 14.7 (Algarve) to 33.0 (Alentejo, table 3). Similar results were obtained for occupation, 
Table 1 Weighted distribution of age, educational and occupational groups, stratified by gender and region, Portuguese health survey 2005-2006, only direct interviews

\begin{tabular}{|c|c|c|c|c|c|c|c|c|}
\hline & North & Centre & Lisbon & Alentejo & Algarve & Azores & Madeira & Portugal \\
\hline $20-39$ & 37.9 & 31.8 & 33.8 & 25.3 & 32.9 & 50.7 & 37.1 & 34.8 \\
\hline 60 or more & 26.4 & 35.7 & 31.1 & 42.8 & 32.5 & 15.0 & 28.2 & 30.5 \\
\hline \multicolumn{9}{|c|}{ Education (completed years) } \\
\hline Less than 5 & 51.5 & 54.4 & 42.1 & 58.5 & 46.7 & 32.0 & 47.3 & 48.5 \\
\hline \multicolumn{9}{|l|}{ Occupation (NCO) } \\
\hline Blue collar & 59.3 & 58.7 & 39.6 & 57.2 & 41.6 & 32.7 & 49.1 & 51.1 \\
\hline Lower white collar & 26.4 & 23.6 & 40.4 & 26.4 & 40.6 & 45.6 & 34.3 & 31.7 \\
\hline Upper white collar & 14.3 & 17.7 & 20.0 & 16.4 & 17.8 & 21.7 & 16.6 & 17.2 \\
\hline \multicolumn{9}{|l|}{ Men } \\
\hline \multicolumn{9}{|l|}{ Age (years) } \\
\hline $20-39$ & 30.6 & 27.1 & 28.6 & 24.2 & 29.7 & 40.5 & 37.6 & 29.3 \\
\hline 12 or more & 6.1 & 11.5 & 16.9 & 6.0 & 7.7 & 6.3 & 9.3 & 10.9 \\
\hline \multicolumn{9}{|l|}{ Occupation (NCO) } \\
\hline Blue collar & 66.3 & 61.9 & 50.5 & 67.7 & 57.1 & 66.5 & 56.6 & 59.6 \\
\hline Lower white collar & 13.0 & 16.0 & 17.8 & 17.4 & 20.1 & 17.8 & 24.0 & 16.0 \\
\hline Upper white collar & 20.7 & 22.1 & 31.7 & 14.9 & 22.7 & 15.8 & 19.4 & 24.4 \\
\hline
\end{tabular}

NCO: National Classification of Occupations (1994). Results are expressed as percentages calculated according to sampling weights. Statistical analysis comparing regions by Pearson chi-square test: all tests have $P<0.0001$.

Table 2 Age-standardized, weighted prevalence of obesity according to educational and occupational groups, by gender and region, Portuguese health survey 2005-2006, only direct interviews

\begin{tabular}{|c|c|c|c|c|c|c|c|c|}
\hline & North & Centre & Lisbon & Alentejo & Algarve & Azores & Madeira & Portugal \\
\hline \multicolumn{9}{|l|}{ Women } \\
\hline Overall prevalence & 16.2 & 15.3 & 19.4 & 20.6 & 11.6 & 18.1 & 14.9 & 17.2 \\
\hline \multicolumn{9}{|c|}{ Education (completed years) } \\
\hline Less than 5 & 21.6 & 20.3 & 28.7 & 25.5 & 15.8 & 31.6 & 20.6 & 23.6 \\
\hline $5-11$ & 11.7 & 9.3 & 12.4 & 15.3 & 9.0 & 12.3 & 10.7 & 11.7 \\
\hline 12 or more & 5.2 & 9.0 & 13.7 & 8.0 & 3.2 & 10.4 & 7.5 & 9.5 \\
\hline$P$ value ${ }^{a}$ & 0.001 & 0.024 & 0.009 & $<0.001$ & 0.02 & 0.001 & 0.06 & $<0.001$ \\
\hline \multicolumn{9}{|l|}{ Occupation } \\
\hline Blue collar & 18.4 & 18.7 & 26.8 & 24.4 & 14.9 & 27.2 & 19.4 & 21.0 \\
\hline Lower white collar & 14.9 & 10.8 & 16.7 & 16.6 & 10.5 & 14.6 & 12.7 & 15.0 \\
\hline Upper white collar & 9.2 & 9.7 & 10.4 & 13.5 & 6.1 & 11.7 & 6.4 & 9.8 \\
\hline$P$ value ${ }^{a}$ & 0.03 & 0.02 & $<0.001$ & 0.003 & 0.03 & 0.001 & 0.05 & $<0.001$ \\
\hline \multicolumn{9}{|l|}{ Men } \\
\hline Overall prevalence & 16.5 & 13.8 & 18.1 & 17.3 & 14.7 & 15.2 & 16.7 & 16.5 \\
\hline \multicolumn{9}{|c|}{ Education (completed years) } \\
\hline Less than 5 & 18.3 & 16.7 & 24.3 & 19.3 & 17.7 & 17.4 & 16.5 & 19.7 \\
\hline $5-11$ & 13.5 & 10.9 & 14.3 & 13.9 & 12.2 & 13.8 & 18.9 & 13.5 \\
\hline 12 or more & 20.2 & 9.5 & 13.6 & 19.1 & 9.7 & 8.7 & 8.9 & 14.1 \\
\hline$P$ value ${ }^{a}$ & 0.33 & 0.04 & 0.051 & 0.77 & 0.06 & 0.54 & 0.70 & 0.16 \\
\hline \multicolumn{9}{|l|}{ Occupation } \\
\hline Blue collar & 16.7 & 13.1 & 19.9 & 18.5 & 14.3 & 16.1 & 18.5 & 17.0 \\
\hline Lower white collar & 18.3 & 17.5 & 16.6 & 15.7 & 17.1 & 15.2 & 17.3 & 17.2 \\
\hline Upper white collar & 14.9 & 13.1 & 16.0 & 13.7 & 13.4 & 11.3 & 10.7 & 14.9 \\
\hline$P$ value ${ }^{a}$ & 0.72 & 0.89 & 0.30 & 0.34 & 0.89 & 0.19 & 0.13 & 0.34 \\
\hline
\end{tabular}

Results are expressed as percentages calculated according to sampling weights.

${ }^{a} P$ values for trend across socioeconomic categories, adjusting for age categories.

blue collar women being 2.2 times more likely to be obese than their white upper collar counterparts; again, large regional variations in RII and SII were found (table 3). Conversely, no consistent educational or occupational gradients were found for men, as the majority of RIIs included unity and the majority of SIIs included zero in their $95 \%$ confidence intervals (table 3 ).
The effect of regional gross domestic product, regional percentage of the population living in an urban setting, and regional unemployment rate on RII and SII for Portugal are provided in table 4. No particular effect was found for any of the three covariates, as the estimates for RII and SII were comparable to those obtained adjusting for age only (table 4). 
Table 3 Relative and absolute educational and occupational inequalities across economic regions in Portugal, stratified by gender, Portuguese health survey 2005-2006, only direct interviews

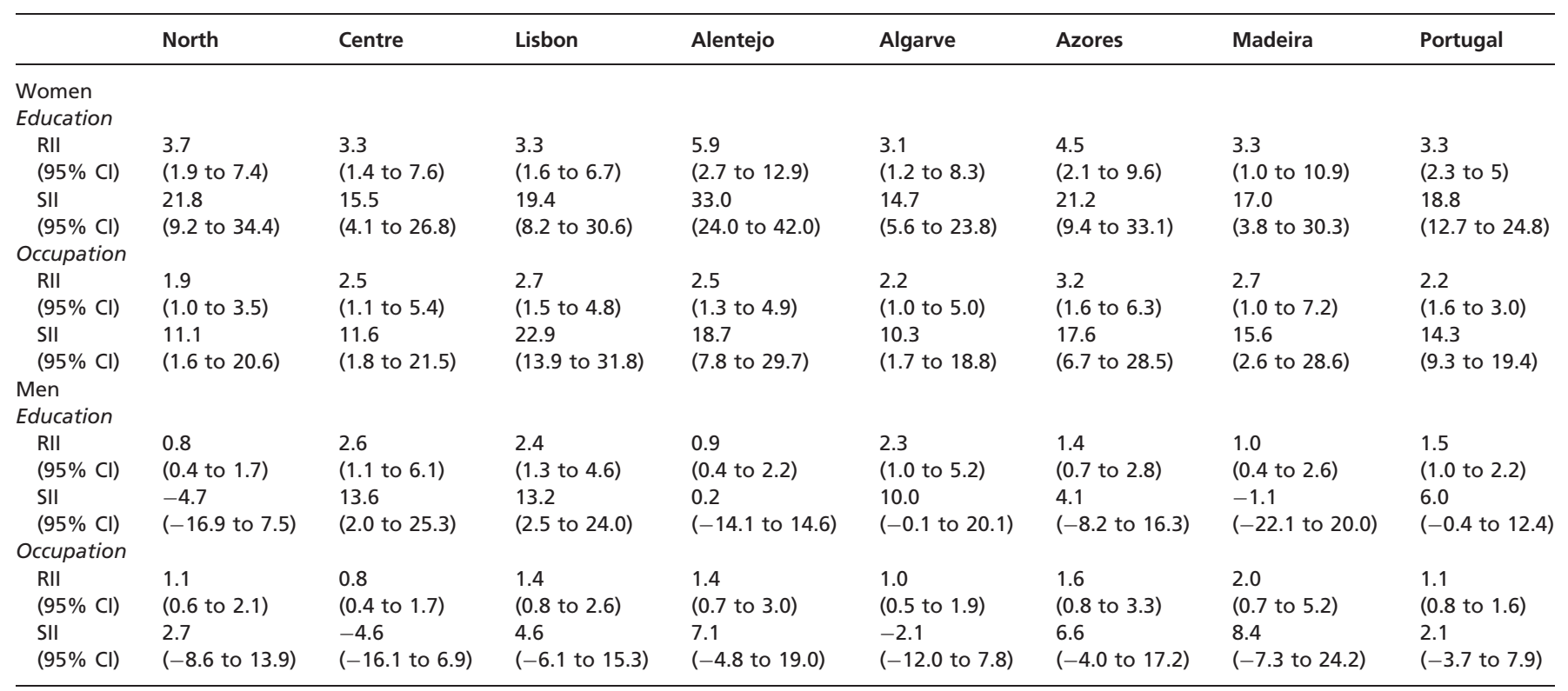

95\% Cl, 95\% confidence interval; RIl, relative index of inequality; SIl, slope index of inequality. Rlls and Slls can be interpreted as the prevalence ratio or difference in obesity between the extremes of the educational distribution, respectively.

Table 4 Relative and absolute educational and occupational inequalities in Portugal, stratified by gender, Portuguese health survey 2005-2006, only direct interviews

\begin{tabular}{|c|c|c|c|c|c|}
\hline & Model 1 & Model 2 & Model 3 & Model 4 & Model 5 \\
\hline Education & & & & & \\
\hline RII $(95 \% \mathrm{Cl})$ & 3.3 (2.3 to 5.0$)$ & 3.6 (2.4 to 5.3 ) & 3.5 (2.4 to 5.2$)$ & 3.5 (2.3 to 5.2$)$ & 3.6 (2.4 to 5.3 ) \\
\hline \multicolumn{6}{|l|}{ Occupation } \\
\hline RII $(95 \% \mathrm{Cl})$ & 2.2 (1.6 to 3 ) & 2.4 (1.7 to 3.3 ) & 2.3 (1.6 to 3.2 ) & 2.3 (1.6 to 3.2 ) & 2.4 (1.7 to 3.3$)$ \\
\hline SII $(95 \% \mathrm{Cl})$ & 14.3 (9.3 to 19.4$)$ & 14.7 (9.8 to 19.6$)$ & 14.3 (9.4 to 19.1$)$ & $14.2(9.3$ to 19$)$ & 14.6 (9.7 to 19.5$)$ \\
\hline RII $(95 \% \mathrm{Cl})$ & 1.5 (1.0 to 2.2$)$ & 1.6 (1.1 to 2.4$)$ & $1.6(1.1$ to 2.4$)$ & $1.6(1.1$ to 2.3$)$ & $1.6(1.1$ to 2.4$)$ \\
\hline SII $(95 \% \mathrm{CI})$ & $6.0(-0.4$ to 12.4$)$ & 6.6 (0.1 to 13.1$)$ & $6.7(0.3$ to 13.1$)$ & $6.5(0.1$ to 12.9$)$ & $6.7(0.3$ to 13.1$)$ \\
\hline \multicolumn{6}{|l|}{ Occupation } \\
\hline RII $(95 \% \mathrm{Cl})$ & 1.1 (0.8 to 1.6$)$ & 1.2 (0.8 to 1.7$)$ & $1.2(0.8$ to 1.7$)$ & $1.2(0.8$ to 1.7$)$ & $1.2(0.8$ to 1.7$)$ \\
\hline SII $(95 \% \mathrm{Cl})$ & $2.1(-3.7$ to 7.9$)$ & $2.6(-3.2$ to 8.4$)$ & $2.5(-3.2$ to 8.2$)$ & $2.2(-3.5$ to 7.9$)$ & $2.4(-3.3$ to 8.1$)$ \\
\hline
\end{tabular}

95\% Cl, 95\% confidence interval; RII, relative index of inequality; SII, slope index of inequality. Rlls and Slls can be interpreted as the prevalence ratio or difference in obesity between the extremes of the educational distribution, respectively. Model 1: Adjusted for age categories; Model 2: Adjusted for age categories and regional Gross Domestic Product; Model 3: Adjusted for age categories and regional percentage of the population living in an urban setting; Model 4: Adjusted for age categories and regional unemployment rate; Model 5: Adjusted for age categories, regional Gross Domestic Product, regional percentage of the population living in an urban setting and regional unemployment rate.

\section{Sensitivity analyses}

Sensitivity analyses were carried out by including all eligible interviews, i.e. direct and proxy. The results are provided in supplementary tables S4-9. Overall and regional prevalence of obesity was lower (supplementary table S7), but the associations with education and occupational status remained (supplementary tables S7-9).

\section{Discussion}

To our knowledge, this is the first description of regional variations in relative and absolute socioeconomic inequalities in obesity performed in Portugal. Our results show that among women, the prevalence of obesity is high and varies substantially across regions, with large social inequalities that also varied across regions.
Conversely, in men, no significant variation in the prevalence of obesity was found, and no clear graded pattern was observed, although obesity was more common among men with a low educational or occupational level in all regions.

\section{Associations between SEP and obesity}

Prevalence of obesity was higher in the lower SEP groups, namely among women. The association between SEP and obesity might result from several relationships: (a) a causal relation; (b) a reverse relation indicating that obesity leads to lower SEP and (c) no causal effect, with the observed association being explained by unobserved factors related to both obesity and SEP. ${ }^{24}$ For instance, Cutler and Lleras-Muney argue that a disadvantaged health status in childhood leads to lower levels of education which, in turn, lead to 
disadvantaged health status in adulthood. Factors like family or genetic background are other plausible unobserved factors that might explain the relationship between education and obesity. ${ }^{25}$ Still, although the causal relation between education and obesity has not been definitely proven, most of the effect of education on obesity seems to be direct. ${ }^{26}$ The protective effect of education is likely related to a greater access and ability to manage health-related information, to a greater perception of the risks of certain lifestyle choices and improved self-control, consistency of preferences over time and self-esteem. ${ }^{24}$

\section{Relative and absolute educational inequalities in obesity}

Approximately one out of six Portuguese were obese, a prevalence rate which has been increasing regularly since 1995 (5), the increase being more prominent in women and in younger ages. ${ }^{4}$ We observed larger relative and absolute educational and occupational inequalities in women than in men, a finding in agreement with previous reports. ${ }^{11,27}$ The educational inequalities in women could partly be due to societal stereotypes, women of high SEP having more pressure to be thin and achieving a better weight control than their lesser educated peers. ${ }^{28}$ Gender differences in physical activity patterns in the most disadvantaged socioeconomic groups may explain these differences as unskilled jobs, in which typically men engage more frequently, tend to be more physically demanding. Still, non-behavioural factors may also play a role: lower SEP women are more vulnerable than men to unfavourable psychosocial and material exposures over the life course, ${ }^{29}$ which might influence adiposity through disturbances in physiological stress systems. ${ }^{30}$ Further, within the same SEP, women tend to get lower wages than men, which could amplify these mechanisms. ${ }^{31}$ Gender differences may also be partly explained by a reverse causation mechanism. Overweight during adolescence and early adulthood may lead to more severe socioeconomic consequences among women than among men. For instance, compared to men, overweight women complete fewer years of school, have lower wages and higher rates of household poverty. ${ }^{32}$ The implications of the gender differences in socioeconomic gradients are considerable. As women belonging to disadvantaged socioeconomic groups are more likely to be obese, it is plausible that they are also more likely to give birth and raise children who will themselves become obese. $^{33}$ These children may perpetuate the socioeconomic gap in obesity as they will have fewer chances of upwards social mobility. ${ }^{34}$ The intergenerational transmission of obesity is plausibly modifiable if we are able to decrease the prevalence of obesity among women. Furthermore, actions targeting the vulnerability to obesity of the low SEP groups will not only decrease inequalities per se, but will also potentially prevent part of the morbidity, mortality and economic burden associated with this condition.

Importantly, differences in educational inequalities across regions were similar to those observed between countries. Specifically, in a previous study that compared educational inequalities in selfreported obesity across European countries, the RIIs among women varied from 1.5 in Latvia to 6.78 in Portugal. ${ }^{35}$ In the current study, the RIIs varied from 3.1 in the Centre region to 5.9 in Alentejo. No important changes were found after adjusting for regional characteristics such as gross domestic product, percentage of the population living in an urban setting, or unemployment rate. These findings suggest that the regional heterogeneity of inequalities in obesity is not dependent on such socioeconomic characteristics. Interestingly, the previous study also showed no effect of socioeconomic development on obesity prevalence in women, but not in men. ${ }^{35}$ Thus, it is likely that the regional heterogeneity of inequalities in obesity in Portugal is driven by other unmeasured factors that should be further assessed. This study shows that the direct evaluation of inequalities at the country level may hide important within-country variations. Thus, the implementation of national policies aimed to reduce inequalities in health outcomes should consider the regional specificities within each country.

\section{Strengths and limitations}

This study used a nationally representative sample of the Portuguese population. This allowed us to provide an updated picture of educational and occupational inequalities in obesity in Portugal. Also, this is one of the first studies to quantify regional variations in educational and occupational inequalities within a country.

However, some methodological limitations warrant discussion. First, the use of self-reported data leads to a likely underestimation of the prevalence of obesity. ${ }^{36}$ Still, in a previous study of urban Portuguese adults, the magnitude of misreporting was smaller among women with the highest level of education. ${ }^{37}$ If a similar reporting bias applies to the current study, the RIIs and SIIs among women might be underestimated and the real educational and occupational differences in obesity levels might be even larger than reported. Interestingly, using all eligible data showed that proxies tended to underestimate obesity levels (supplementary table S10) but this led to an increase (in women) and to a decrease (in men) of the estimated RIIs and SIIs; hence, underestimation of obesity does not have the same impact according to gender. Second, the cross-sectional nature of the current analysis limits our ability to address the issue of causality, which can only be assessed in a prospective study. Although limited in its geographical setting (city of Porto, North or Portugal), the ongoing EpiPorto prospective study ${ }^{38}$ might provide more information in the near future. Third, the non-linear association between occupation and obesity among men in some regions might have limited the ability of RIIs/SIIs to summarize relative and absolute inequalities. Fourth, the data relate to the period 2005-2006 and it would be of interest to compare it to data collected during or after the financial crisis that raised unemployment rates from $7.6 \%$ in $2006-12.7 \%$ in 2011 (17) and led to considerable changes in health. ${ }^{39}$ Finally, a sizable number of participants for whom no occupational data was available were excluded from the study, reducing sample size and thus statistical power.

\section{Conclusion}

In Portugal, prevalence of obesity varies considerably between educational groups, the differences being larger in women than in men. In women, the differences between educational groups also show considerable variation between regions, while no such variation was found in men.

\section{Supplementary data}

Supplementary data are available at EURPUB online.

\section{Acknowledgements}

SS is supported by an Ambizione Grant (n PZ00P3_147998) from the Swiss National Science Foundation (SNSF). HB received a grant (SFRH/BSAB/113778/2015) from Fundação para a Ciência e Tecnologia (FCT).

\section{Funding}

S.S. is supported by an Ambizione Grant (n PZ00P3_147998) from the Swiss National Science Foundation (SNSF). H.B. received a grant (SFRH/BSAB/113778/2015) from Fundação para a Ciência e Tecnologia (FCT).

Conflicts of interest: None declared. 


\section{Key points}

- The prevalence of obesity varied substantially across regions among Portuguese women, but not among men.

- The prevalence of obesity increased with decreasing levels of education and occupation among Portuguese women, but not among men.

- Large regional variations in both absolute and relative educational inequalities in obesity were found among Portuguese women.

- In Portugal, regional variations in educational inequalities in obesity were similar in magnitude to those previously observed between countries.

\section{References}

1 Finucane MM, Stevens GA, Cowan MJ, et al. National, regional, and global trends in body-mass index since 1980: systematic analysis of health examination surveys and epidemiological studies with 960 country-years and 9.1 million participants. Lancet 2011;377:557-67.

2 World Health Organization. WHO global strategy on diet, physical activity and health: a framework to monitor and evaluate implementation. Geneva, Switzerland: World Health Organization, 2008.

3 Berghofer A, Pischon T, Reinhold T, et al. Obesity prevalence from a European perspective: a systematic review. BMC Public Health 2008;8.

4 Carreira H, Pereira M, Azevedo A, Lunet N. Trends of BMI and prevalence of overweight and obesity in Portugal (1995-2005): a systematic review. Public Health Nutr 2012;15:972-81.

5 Marques-Vidal P, Paccaud F, Ravasco P. Ten-year trends in overweight and obesity in the adult Portuguese population, 1995 to 2005. BMC Public Health 2011;11.

6 Instituto Nacional de Estatística IP: Inquérito nacional de saúde 2005/2006. Lisboa: Instituto Nacional de Saúde Doutor Ricardo Jorge IP, 2009. 330 p.

7 Wang Y, Beydoun MA. The obesity epidemic in the United States-gender, age, socioeconomic, racial/ethnic, and geographic characteristics: a systematic review and meta-regression analysis. Epidemiol Rev 2007;29:6-28.

8 Santos AC, Barros H. Prevalence and determinants of obesity in an urban sample of Portuguese adults. Public Health 2003;117:430-7.

9 Singh-Manoux A, Gourmelen J, Lajnef M, et al. Prevalence of educational inequalities in obesity between 1970 and 2003 in France. Obes Rev 2009;10:511-8.

10 El Ati J, Traissac P, Delpeuch F, et al. Gender obesity inequities are huge but differ greatly according to environment and socio-economics in a north african setting: a national cross-sectional study in Tunisia. Plos One 2012;7:e48153.

11 Devaux M, Sassi F. Social inequalities in obesity and overweight in 11 OECD countries. Eur J Public Health 2012.

12 Faeh D, Bopp M. Educational inequalities in mortality and associated risk factors: German-versus French-speaking Switzerland. Bmc Public Health 2010;10:567.

13 Oakes JM, Kaufman JS. Methods in Social Epidemiology. 1st edn. San Francisco, CA: Jossey-Bass, 2006.

14 Nomenclature of Units for Territorial Statistics (NUT): Eurostat; 2013. Available at: http://epp.eurostat.ec.europa.eu/portal/page/portal/nuts_nomenclature/introduction (31 Jul 2013, date last accessed).

15 Regional gross domestic product (PPS per inhabitant) by NUTS 2 regions [Internet]. European Commission, 2016 [cited]. Available at: http://ec.europa.eu/ eurostat $/$ tgm $/$ table.do? tab $=$ table\&init $=1$ \&plugin $=1$ \&language $=$ en $\&$ pcode $=$ tgs 00005 (5 July 2016, date last accessed).

16 Instituto Nacional de Estatística IP. Inquérito às Despesas das Famílias 2005/2006. Lisboa, Portugal, 2008. 135 p.

17 PORDATA. Taxa de desemprego: total e por sexo (\%) - Portugal Lisboa, Portugal: Fundação Francisco Manuel dos Santos, 2016. Available at: http://www.pordata. $\mathrm{pt} /$ Municipios/Taxa+de+desemprego + segundo+os+Censos+total $+\mathrm{e}+$ por + sexo+ (percentagem)-405.

18 World Health Organization. Obesity: preventing and managing the global epidemic: report of a WHO consultation. Geneva: World Health Organization, 2000.

19 Mackenbach JP, Kunst AE. Measuring the magnitude of socio-economic inequalities in health: An overview of available measures illustrated with two examples from Europe. Soc Sci Med 1997;44:757-71.

20 Stringhini S, Spencer B, Marques-Vidal P, et al. Age and gender differences in the social patterning of cardiovascular risk factors in Switzerland: the CoLaus study. Plos One 2012;7:e49443.

21 Munoz-Arroyo R, Sutton M. Measuring socio-economic inequalities in health: a practical guide. Edinburgh: Scottish Public Health Observatory (ScotPHO) 2007.

22 Khang YH, Yun SC, Lynch JW. Monitoring trends in socioeconomic health inequalities: it matters how you measure. BMC Public Health 2008;8:66.

23 Spiegelman D, Hertzmark E. Easy SAS calculations for risk or prevalence ratios and differences. Am J Epidemiol 2005;162:199-200.

24 Devaux M, Sassi F, Church J, et al. Exploring the relationship between education and obesity. OECD Journal: Economic Studies 2011;121-59.

25 Cutler DM, Lleras-Muney A. Education and health: evaluating theories and evidence. In: House J, Schoeni R, Kaplan G, Pollack H, editors. Making Americans Healthier: Social and Economic Policy as Health Policy. New York, NY: Russell Sage Foundation, 2008.

26 Marmot MG. The status syndrome: how social standing affects our health and longevity. 1st edn. New York, NY: Times Books, 2004.

27 Mackenbach JP, Stirbu I, Roskam AJ, et al. Socioeconomic inequalities in health in 22 European countries. N Engl J Med 2008;358:2468-81.

28 Williams L, Germov J, Young A. The effect of social class on mid-age women's weight control practices and weight gain. Appetite 2011;56:719-25.

29 Novak M, Ahlgren C, Hammarstrom A. A life-course approach in explaining social inequity in obesity among young adult men and women. Int J Obesity 2006;30:191-200.

30 Rosmond R, Bjorntorp P. Occupational status, cortisol secretory pattern, and visceral obesity in middle-aged men. Obes Res 2000;8:445-50.

31 A evolução das desigualdades entre salários masculinos e femininos: um percurso irregular. In: Ferreira V, editor. A igualdade de mulheres e homens no trabalho e no emprego em Portugal: politicas e circunstâncias. Estudos. Lisboa, Portugal: Comissão para a Igualdade no Trabalho e no Emprego (CITE); 2010. p. 139-90.

32 Conley D, Glauber R. Gender, body mass, and socioeconomic status: new evidence from the PSID. Adv Health Econ Health Serv Res 2007;17:253-75.

33 Whitaker KL, Jarvis MJ, Beeken RJ, et al. Comparing maternal and paternal intergenerational transmission of obesity risk in a large population-based sample. Am J Clin Nutr 2010;91:1560-7.

34 Whitaker RC, Wright JA, Pepe MS, et al. Predicting obesity in young adulthood from childhood and parental obesity. N Engl J Med 1997;337:869-73.

35 Roskam AJR, Kunst AE, Van Oyen H, et al. Comparative appraisal of educational inequalities in overweight and obesity among adults in 19 European countries. Int J Epidemiol 2010;39:392-404.

36 Carreira H, Pereira M, Azevedo A, Lunet N. Effect of the type of population on estimates of mean body mass index and prevalence of overweight and obesity: a systematic review of studies of Portuguese adults. Ann Hum Biol 2012;39:223-38.

37 Ramos E, Lopes C, Oliveira A, Barros H. Unawareness of weight and height-the effect on self-reported prevalence of overweight in a population-based study. J Nutr Health Aging 2009;13:310-4.

38 Pereira M, Lunet $\mathrm{N}$, Paulo $\mathrm{C}$, et al. Incidence of hypertension in a prospective cohort study of adults from Porto, Portugal. BMC Cardiovasc Disord 2012;12:114.

39 Baumbach A, Gulis G. Impact of financial crisis on selected health outcomes in Europe. Eur J Public Health 2014;24:399-403. 